\title{
Composição de aminoácidos de cultivares de feijão e aplicações para o melhoramento genético
}

\author{
Nerinéia Dalfollo Ribeiro(1), Patrícia Medianeira Grigoletto Londero(1), Alberto Cargnelutti Filho(2), Evandro Jost ${ }^{(1)}$, \\ Nerison Luis Poersch ${ }^{(1)}$ e Carlos Augusto Mallmann ${ }^{(3)}$
}

\begin{abstract}
(1)Universidade Federal de Santa Maria (UFSM), Dep. de Fitotecnia, CEP 97105-900 Santa Maria, RS. E-mail: neiadr@smail.ufsm.br, patricialondero@yahoo.com.br, evandrojost@yahoo.com.br, nerisonp@yahoo.com.br (2)Universidade Federal do Rio Grande do Sul, Dep. de Estatística, CEP 91509-900 Porto Alegre, RS. E-mail: cargnelutti@ufrgs.br(3)UFSM, Dep. de Medicina Veterinária Preventiva. E-mail:mallmann@lamic.ufsm.br
\end{abstract}

\begin{abstract}
Resumo - O objetivo deste trabalho foi determinar a composição de aminoácidos em grãos de cultivares de feijão e a presença de interação cultivares $x$ locais, nos teores de aminoácidos, e identificar cultivares para uso direto na alimentação e derivações em programas de melhoramento. Os aminoácidos foram determinados por cromatografia líquida de alta performance (HPLC), em grãos de 19 cultivares de feijão cultivadas em dois locais. Os dados médios obtidos para cada cultivar, em duplicata, foram comparados entre si com a utilização do teste $\mathrm{t}$, a $5 \%$ de probabilidade para cada local. Os grãos das cultivares analisadas apresentaram teores de aminoácidos essenciais e não-essenciais, adequados às necessidades diárias de um indivíduo adulto, o que indica alta qualidade da proteína do feijão. As cultivares de feijão apresentam, em ordem decrescente, os aminoácidos essenciais: leucina, lisina, fenilalanina, valina, isoleucina, treonina, histidina e metionina; e os aminoácidos não-essenciais: ácido glutâmico, ácido aspártico, arginina, serina, alanina, glicina, tirosina, prolina e cisteína. Os teores de leucina, isoleucina, histidina, valina, treonina, glicina e alanina foram afetados pela interação cultivares x locais. A cultivar Iraí apresenta composição de aminoácidos adequada e é indicada para uso em dietas e derivações em programas de melhoramento.
\end{abstract}

Termos para indexação: qualidade protéica, variabilidade genética, interação genótipo x ambiente, seleção.

\section{Amino acid composition in common bean cultivars and applications for genetic breeding}

\begin{abstract}
The objective of this work was to determine the amino acid composition of seeds of common bean cultivars and to examine the presence of cultivar $\mathrm{x}$ location interactions in amino acid contents, and to identify common bean cultivars for direct consumption or use in breeding programs. The amino acid contents were determinated through high performance liquid chromatography (HPLC), in 19 common bean cultivars obtained in two localities. The mean data sets of each cultivar, in duplication, were compared by the $\mathrm{F}$ test at $5 \%$ probability for each location. Grains of the common bean cultivars analyzed showed essential and nonessential amino acids contents appropriate for daily supply requirements of human adults, which indicates the high quality of common bean protein. The common bean cultivars were constituted mainly of the following essencial amino acids: leucine, lysine, phenylalanine, valine, isoleucine, threonine, histidine and methionine; and, also, the following nonessencial amino acids: glutamic acid, aspartic acid, arginine, serine, alanine, glycine, tyrosine, proline and cysteine. The leucine, isoleucine, histidine, valine, threonine, glycine and alanine contents were affected by the cultivar x location interactions. Cultivar Iraí presents amino acid content suitable for diet enrichment and germplasm improvement.
\end{abstract}

Index terms: protein quality, genetic variability, genotype x environment interaction, selection.

\section{Introdução}

As fontes de proteína de origem vegetal têm sido amplamente utilizadas para a alimentação humana, em razão do baixo custo e ao menor teor de gordura, quando comparados aos alimentos de origem animal. $\mathrm{O}$ feijão (Phaseolus vulgaris L.) apresenta cerca da metade do teor de proteína em relação à soja, porém é de maior digestibilidade protéica $(78,70 \%)$ (Pires et al., 2006).
A proteína considerada de boa qualidade ou de alto valor biológico é aquela que fornece maior digestibilidade e quantidades adequadas de aminoácidos essenciais (Morales de Leon et al., 2005; Pires et al., 2006). Para o ser humano, são essenciais os aminoácidos: isoleucina, leucina, lisina, metionina, fenilalanina, treonina, triptofano, histidina e valina (Franco, 2005). A ausência ou a deficiência de um aminoácido interfere de tal forma no processo de constituição da proteína que pode levar à 
caracterização da dieta como aprotéica (Szarfarc et al., 1980).

O feijão é um alimento que apresenta em sua constituição todos os aminoácidos essenciais; é rico em lisina, mas limitante em aminoácidos sulfurados metionina e cisteína (Fonseca Marques \& Bora, 2000; Guzmán-Maldonado et al., 2000; Pires et al., 2006). Por isso, a combinação com cereais se faz necessária, para que se obtenha uma dieta com conteúdo de aminoácidos mais adequados aos requisitos nutricionais da espécie humana.

Como o consumo de feijão faz parte dos hábitos alimentares de grande parcela da população, é importante considerar que o aumento dos teores de aminoácidos essenciais e não-essenciais, por meio de métodos clássicos de melhoramento, poderá fazer com que esse alimento seja ainda mais nutritivo. Para isso, é preciso que haja variabilidade genética, para a composição de aminoácidos em feijão, e trabalhos conduzidos em vários países evidenciam que há diferenças genéticas no germoplasma (Evans \& Bandemer, 1967; Kelly \& Bliss, 1975a; Abd-El-Samei \& Lásztity, 1984; Fonseca Marques \& Bora, 2000). No Brasil, o perfil de aminoácidos de apenas quatro cultivares de feijão é conhecido (Antunes et al., 1995). Não se conhece, na literatura, informação sobre a composição de aminoácidos das cultivares de feijão usadas para o cultivo atualmente no Brasil.

Além disso, correlação positiva entre o teor de metionina e a porcentagem de proteína $(\mathrm{r}=0,33)$ foi observada em populações segregantes de feijão (Kelly \& Bliss, 1975a). Portanto, é possível que o aumento do teor de determinado aminoácido propicie incremento no teor de proteína e, como conseqüência, uma dieta de maior valor protéico poderá ser obtida.

Para que seja possível o desenvolvimento de cultivares de feijão com teores elevados de aminoácidos, é necessário o conhecimento da composição de aminoácidos dos grãos das cultivares brasileiras e dos efeitos da interação genótipos x ambientes sobre essas características.

O objetivo deste trabalho foi determinar a composição de aminoácidos essenciais e não-essenciais em grãos de cultivares de feijão, desenvolvidas pela pesquisa no Brasil, e determinar a presença de interação cultivares $x$ locais sobre os teores de aminoácidos, além de identificar cultivares com teores adequados de aminoácidos, para uso direto na alimentação ou para derivações em programas de melhoramento.

\section{Material e Métodos}

Os grãos de 19 cultivares de feijão foram obtidos de experimentos conduzidos em dois municípios do Estado do Rio Grande do Sul (RS), no cultivo de safra agrícola de 2004/2005. Em Santa Maria, o experimento foi realizado em área da Universidade Federal de Santa Maria (UFSM), na região da depressão central do RS, a $95 \mathrm{~m}$ de altitude, latitude $29^{\circ} 42^{\prime} \mathrm{S}$ e longitude $53^{\circ} 43^{\prime} \mathrm{W}$. O clima da região é do tipo Cfa, temperado chuvoso, com chuvas bem distribuídas ao longo dos anos, e subtropical do ponto de vista térmico. O solo é classificado como Alissolo Hipocrômico argilúvico típico, pertencente à unidade de mapeamento Santa Maria, com a seguinte composição química: $\mathrm{pH}\left(\mathrm{H}_{2} \mathrm{O}\right) 5,8$ e matéria orgânica $1,9 \%$.

$\mathrm{O}$ experimento foi conduzido em área da Embrapa Clima Temperado, em Pelotas, na Região Sul do Estado do RS, a $17 \mathrm{~m}$ de altitude, $31^{\circ} 7 \mathrm{~S}$ e $52^{\circ} 1^{\prime} \mathrm{W}$. O clima também é subtropical do tipo $\mathrm{Cfa}$, e o solo da região é caracterizado como Cambissolo Háplico distrófico típico e apresentava $\mathrm{pH}\left(\mathrm{H}_{2} \mathrm{O}\right)$ de 5,1 e matéria orgânica de $3,5 \%$.

Ambos os experimentos receberam preparo do solo de maneira convencional, e a adubação foi realizada com base na interpretação da análise química do solo (Rolas, 1995). Em Santa Maria, foram necessários $250 \mathrm{~kg} \mathrm{ha}^{-1}$ da fórmula 5-20-20, incorporada na semeadura, e $40 \mathrm{~kg} \mathrm{ha}^{-1} \mathrm{de} \mathrm{N}$ na forma de uréia, aplicado em cobertura. A adubação de cobertura foi parcelada em duas aplicações, que foram efetuadas nos estádios vegetativos de primeira e de terceira folhas trifolioladas, V3 e V4, respectivamente. Em Pelotas, usaram-se apenas $300 \mathrm{~kg} \mathrm{ha}^{-1}$ da fórmula 10-30-10, e não foi necessária a adubação de cobertura com $\mathrm{N}$.

$\mathrm{O}$ controle de insetos foi realizado com a aplicação de Metamidofós, e o controle de plantas invasoras foi manual e efetuado sempre que necessário, de maneira que a cultura não sofresse competição (Comissão Estadual de Pesquisa de Feijão, 2003). O controle de doenças e a irrigação não foram realizados.

O delineamento experimental de blocos ao acaso, com três repetições, foi utilizado no campo em ambos os locais de cultivo. As parcelas foram compostas por quatro fileiras de $4 \mathrm{~m}$ de comprimento, espaçadas de $0,50 \mathrm{~m}$, e $\mathrm{a}$ área útil da parcela consistiu das duas fileiras centrais, nas quais se desprezaram $0,50 \mathrm{~m}$ das extremidades, o que totalizou $3 \mathrm{~m}^{2}$ por unidade experimental. 
A colheita e a trilha das plantas foram realizadas manualmente na maturação fisiológica e, logo após a retirada das impurezas, os grãos foram secados ao sol e em estufa $\left(65\right.$ a $\left.70^{\circ} \mathrm{C}\right)$, até umidade de $13 \%$. Amostras de $150 \mathrm{~g}$ de grãos foram tomadas ao acaso e moídas em micromoinho até a obtenção de partículas inferiores a $1 \mathrm{~mm}$. A seguir, essas amostras foram armazenadas em embalagens plásticas, devidamente identificadas, e conservadas sob refrigeração até a realização das análises.

A determinação dos teores de aminoácidos foi realizada no Laboratório de Análises Micotoxicológicas (LAMIC), da UFSM, Santa Maria, RS, por cromatografia líquida de alta performance (HPLC). As amostras passaram por hidrolisação prévia com ácido clorídrico $(\mathrm{HCl})$ bidestilado $6 \mathrm{~N}$, seguida de derivação pré-coluna dos aminoácidos livres com fenilisotiocianato (PITC), e a separação dos derivativos feniltiocarbamilaminoácidos (PTC-aa), em coluna de fase reversa C18 (Pico-Tag - 3,9x300 mm), com detecção por UV a $254 \mathrm{~nm}$. A quantificação da amostra foi baseada na altura de cada pico de aminoácido, tendo-se usado como referência a altura do pico do padrão interno de aminoácidos com concentração conhecida, com o padrão derivado nas mesmas condições e no mesmo tempo das amostras. Os teores de aminoáciodos foram transformados para gramas por $16 \mathrm{~g} \mathrm{de} \mathrm{N} \mathrm{da}$ amostra seca. Para isso, o teor de proteína bruta (PB, g por $100 \mathrm{~g}$ de matéria seca - MS) da amostra foi determinada pelo método de micro-Kjeldahl (Nx6,25), com o uso da metodologia descrita pela Association of Official Agricultural Chemists (1995). Os teores de aminoácidos e de proteína bruta foram quantificados em duplicata.

Os dados médios obtidos para cada cultivar, em cada local, foram comparados entre si com a utilização do teste t, a $5 \%$ de probabilidade. Determinou-se a matriz de distância euclidiana média, entre as 19 cultivares de feijão, que foi utilizada como medida de dissimilaridade para a análise de agrupamento pelo método do vizinho mais distante (Cruz \& Regazzi, 2001). Com os dados de cada cultivar, na média dos locais (Santa Maria e Pelotas), estimou-se a matriz de coeficientes de correlação fenotípica de Pearson (r), entre os aminoácidos essenciais e os não-essenciais. A significância de $r$ foi verificada pelo teste $t$ de Student, a 5\% de probabilidade. As análises foram realizadas com o auxílio do programa Genes (Cruz, 2001).

\section{Resultados e Discussão}

Os grãos das cultivares de feijão apresentaram variações para os teores de aminoácidos essenciais e não-essenciais (Tabelas 1 e 2). Para todas as cultivares avaliadas, foram obtidos teores de aminoácidos superiores ao padrão considerado adequado pela Organização das Nações Unidas para Agricultura e Alimentação (FAO), para suprir as necessidades diárias de um indivíduo adulto (FAO, 1998), fato que indica a alta qualidade da proteína do feijão.

Com relação aos aminoácidos essenciais, os grãos de feijão são constituídos em maior parte por leucina, seguido por lisina, fenilalanina, valina, isoleucina, treonina, histidina e metionina (Tabela 1). Essa composição é muito semelhante ao observado em cultivares de feijão produzidas em outros países (Evans \& Bandemer, 1967; Abd-El-Samei \& Lásztity, 1984; Fonseca Marques \& Bora, 2000; Guzmán-Maldonado et al., 2000) e nas cultivares que já são comercializadas no Brasil (Antunes et al., 1995).

Os teores de leucina, isoleucina, histidina, valina e treonina apresentaram diferença significativa pelo teste $t$, o que indica resposta diferenciada das cultivares de feijão aos locais de avaliação (Tabela 1). Entretanto, os teores de leucina, isoleucina, valina e treonina não variaram em feijão-silvestre, feijão-miúdo e em duas cultivares de feijão, quando cultivados em diferentes locais no México (Guzmán-Maldonado et al., 2000). Esses autores verificaram que os teores de lisina e dos aminoácidos aromáticos (fenilalanina + tirosina) diferiram entre os ambientes. Portanto, os teores de aminoácidos do feijão podem ser alterados em consequiência do genótipo e das condições de cultivo.

O teor de leucina variou de 6,34 (TPS Bonito) a 8,16 g por $16 \mathrm{~g}$ de N da MS (Iraí), em Santa Maria. Por sua vez, em Pelotas, níveis de 6,32 (FTS Magnífico) a 7,06 g por $16 \mathrm{~g}$ de $\mathrm{N}$ da MS (TPS Nobre) foram observados. As cultivares Iraí e TPS Nobre podem ser utilizadas na dieta quando houver necessidade de utilização de alimentos com alto teor de leucina. 
O teor de lisina variou de 5,47 (TPS Bonito) a 8,16 g por $16 \mathrm{~g}$ de $\mathrm{N}$ da MS (Iraí), em Santa Maria, e de 5,81 (Iapar 44) a 6,56 g por $16 \mathrm{~g}$ de $\mathrm{N}$ da MS (Guapo Brilhante), em Pelotas. Alimentos com elevado teor de lisina são desejáveis, em razão de esse aminoácido, juntamente com a arginina e a serina, promover maior absorção do teor de cálcio pelo organismo, porque influencia o pH intestinal e a formação de compostos solúveis cálcio-aminoácidos (Franco, 2005). Portanto, a cultivar Iraí poderia ser incorporada à alimentação com esse objetivo.

A cultivar Iraí se destacou, ainda, pelos elevados teores de fenilalanina, isoleucina, histidina, valina e metionina, obtidos em ambos os locais de cultivo (Tabela 1), por isso pode ser considerada uma cultivar com composição de aminoácidos adequada para uso na alimentação, de acordo com o padrão da FAO (1998). Cardápios mais saudáveis poderão ser elaborados com a inclusão de grãos de feijão da cultivar Iraí, pois vários efeitos benéficos ao organismo têm sido relacionados aos teores de aminoácidos (Costa, 2003). De acordo com essa autora, a leucina, a isoleucina e a valina contribuem na recuperação de traumas múltiplos e de queimaduras, além de ter participação no restabelecimento de processos metabólicos normais, quando o fígado se encontra debilitado.

Todas as cultivares de feijão apresentaram aminoácidos sulfurados (Tabelas 1 e 2) em quantidades adequadas para suprir os requerimentos nutricionais do organismo, segundo o padrão estabelecido pela FAO (FAO, 1998). No entanto, é preciso considerar que os teores apresentados pela FAO são muito baixos. Por isso, no presente trabalho, nenhuma cultivar foi identificada como deficiente em metionina e em cisteína, como era esperado (Evans \& Bandemer, 1967; Kelly \& Bliss, 1975b; Abd-El-Samei \& Lásztity, 1984; Antunes et al., 1995; Fonseca Marques \& Bora, 2000; GuzmánMaldonado et al., 2000; Pires et al., 2006).

A identificação de cultivares de feijão com altos teores de metionina é oportuna, pois esse aminoácido exerce ação lipotrópica (Franco, 2005). Nesse sentido, o uso rotineiro, na alimentação, das cultivares Iraí, Guapo Brilhante e Macotaço, de alto teor de metionina, poderia ter êxito na prevenção do acúmulo de gordura no fígado.

Quanto aos aminoácidos não-essenciais - aqueles que o organismo pode sintetizar em quantidades suficientes -, verificou-se que os grãos de feijão das cultivares em cultivo no Brasil são constituídos, em ordem decrescente

Tabela 1. Composição de aminoácidos essenciais (em gramas por $16 \mathrm{~g}$ de $\mathrm{N}$ da matéria seca) dos grãos de cultivares de feijão cultivadas em Santa Maria (SM) e em Pelotas (Pel), RS.

\begin{tabular}{|c|c|c|c|c|c|c|c|c|c|c|c|c|c|c|c|c|}
\hline \multirow[t]{2}{*}{ Cultivar } & \multicolumn{2}{|c|}{ Lisina } & \multicolumn{2}{|c|}{ Fenilalanina } & \multicolumn{2}{|c|}{ Leucina } & \multicolumn{2}{|c|}{ Isoleucina } & \multicolumn{2}{|c|}{ Histidina } & \multicolumn{2}{|c|}{ Valina } & \multicolumn{2}{|c|}{ Treonina } & \multicolumn{2}{|c|}{ Metionina } \\
\hline & SM & $\mathrm{Pel}$ & SM & Pel & SM & $\mathrm{Pel}$ & SM & $\overline{\mathrm{Pel}}$ & $\overline{\mathrm{SM}}$ & Pel & SM & Pel & SM & Pel & SM & $\mathrm{Pel}$ \\
\hline & \multicolumn{16}{|c|}{ Grupo preto } \\
\hline TPS Bionobre & 6,69 & 6,14 & 5,24 & 4,64 & 6,50 & 6,46 & 4,09 & 3,92 & 2,26 & 1,96 & 4,70 & 4,34 & 4,17 & 3,13 & 0,92 & 0,85 \\
\hline Diamante Negro & 6,57 & 6,01 & 4,95 & 4,62 & 7,23 & 6,61 & 4,29 & 3,92 & 2,20 & 2,05 & 4,60 & 4,07 & 3,79 & 3,26 & 0,93 & 0,85 \\
\hline TPS Nobre & 6,53 & 6,55 & 4,90 & 5,06 & 7,22 & 7,06 & 4,25 & 4,19 & 2,17 & 2,18 & 4,60 & 4,44 & 3,53 & 3,28 & 0,91 & 0,91 \\
\hline Macanudo & 6,45 & 5,95 & 5,06 & 4,73 & 6,79 & 6,88 & 4,21 & 4,05 & 2,35 & 1,99 & 5,06 & 4,47 & 3,82 & 3,57 & 0,73 & 0,80 \\
\hline Rio Tibagi & 6,43 & 6,07 & 4,90 & 4,72 & 6,77 & 6,73 & 4,29 & 4,09 & 2,41 & 2,11 & 4,94 & 4,25 & 3,64 & 3,30 & 0,77 & 0,85 \\
\hline Minuano & 6,28 & 5,96 & 4,77 & 4,54 & 6,60 & 6,39 & 4,26 & 4,01 & 2,39 & 1,85 & 5,01 & 4,44 & 3,66 & 3,64 & 0,88 & 0,73 \\
\hline Macotaço & 6,27 & 6,53 & 4,81 & 5,06 & 6,98 & 6,81 & 4,10 & 4,00 & 2,31 & 2,56 & 4,44 & 4,46 & 3,88 & 4,46 & 0,97 & 1,02 \\
\hline Iapar 44 & 6,26 & 5,81 & 4,63 & 4,47 & 6,64 & 6,40 & 3,80 & 3,91 & 2,14 & 1,99 & 4,15 & 4,13 & 3,60 & 3,23 & 0,97 & 0,90 \\
\hline Guapo Brilhante & 6,25 & 6,56 & 4,99 & 5,15 & 6,73 & 6,63 & 4,21 & 3,90 & 2,47 & 2,12 & 4,56 & 4,28 & 4,17 & 3,60 & 1,00 & 0,84 \\
\hline Guateian 6662 & 6,22 & 6,40 & 4,52 & 4,96 & 6,69 & 6,93 & 3,98 & 4,20 & 2,01 & 2,17 & 4,35 & 4,43 & 3,51 & 3,32 & 0,87 & 0,99 \\
\hline BRS Expedito & 6,18 & 5,97 & 4,67 & 4,63 & 6,99 & 6,61 & 4,11 & 3,93 & 2,11 & 2,01 & 4,32 & 4,08 & 3,41 & 2,86 & 0,88 & 0,98 \\
\hline FTS Soberano & 5,94 & 6,55 & 4,82 & 5,31 & 6,68 & 6,76 & 4,25 & 4,00 & 2,04 & 2,33 & 4,60 & 4,44 & 3,59 & 3,85 & 0,81 & 0,96 \\
\hline \multirow[t]{2}{*}{ BRS Valente } & 5,85 & 5,91 & 5,17 & 4,57 & 6,67 & 6,54 & 3,93 & 4,07 & 2,14 & 1,88 & 4,46 & 4,50 & 4,05 & 3,16 & 0,79 & 0,81 \\
\hline & \multicolumn{16}{|c|}{ Grupo de cor ${ }^{(1)}$} \\
\hline Iraí & 8,16 & 6,24 & 6,10 & 4,77 & 8,16 & 6,52 & 5,18 & 4,10 & 2,57 & 1,93 & 5,73 & 4,56 & 4,67 & 3,44 & 1,15 & 0,77 \\
\hline Iapar 31 & 7,94 & 6,09 & 5,86 & 4,83 & 7,35 & 6,51 & 4,50 & 4,11 & 2,55 & 2,16 & 5,10 & 4,42 & 4,76 & 3,77 & 0,98 & 0,92 \\
\hline Pérola & 6,62 & 6,17 & 4,81 & 4,62 & 6,58 & 6,33 & 4,30 & 3,89 & 2,17 & 2,01 & 4,84 & 4,32 & 3,65 & 3,33 & 0,98 & 0,83 \\
\hline FTS Magnífico & 6,56 & 5,86 & 5,00 & 4,64 & 6,94 & 6,32 & 4,31 & 4,02 & 2,25 & 2,21 & 4,65 & 4,30 & 3,82 & 3,61 & 0,92 & 0,81 \\
\hline Carioca & 6,17 & 6,24 & 4,64 & 4,73 & 6,43 & 6,48 & 4,00 & 3,96 & 2,17 & 2,03 & 4,49 & 4,31 & 3,70 & 3,54 & 0,86 & 0,88 \\
\hline TPS Bonito & 5,47 & 6,16 & 4,17 & 4,95 & 6,34 & 6,73 & 3,86 & 4,17 & 2,18 & 2,22 & 4,13 & 4,44 & 3,82 & 3,80 & 0,76 & 0,81 \\
\hline Média & 6,46 & 6,17 & 4,95 & 4,79 & $6,86^{*}$ & $6,62 *$ & $4,21^{*}$ & $4,02 *$ & $2,26^{*}$ & $2,09 *$ & $4,67^{*}$ & $4,35^{*}$ & $3,85^{*}$ & $3,48^{*}$ & 0,90 & 0,87 \\
\hline Valor máximo & 8,16 & 6,56 & 6,10 & 5,31 & 8,16 & 7,06 & 5,18 & 4,20 & 2,57 & 2,56 & 5,73 & 4,56 & 4,76 & 4,46 & 1,15 & 1,02 \\
\hline Valor mínimo & 5,47 & 5,81 & 4,17 & 4,47 & 6,34 & 6,32 & 3,80 & 3,89 & 2,01 & 1,85 & 4,13 & 4,07 & 3,41 & 2,86 & 0,73 & 0,73 \\
\hline Desvio-padrão & 0,63 & 0,25 & 0,44 & 0,23 & 0,42 & 0,21 & 0,29 & 0,10 & 0,17 & 0,17 & 0,38 & 0,14 & 0,37 & 0,35 & 0,10 & 0,08 \\
\hline Adequado $^{(2)}$ & \multicolumn{2}{|c|}{1,6} & \multicolumn{2}{|c|}{$1,9^{(3)}$} & \multicolumn{2}{|c|}{1,9} & \multicolumn{2}{|c|}{1,3} & \multicolumn{2}{|c|}{1,6} & \multicolumn{2}{|c|}{1,3} & \multicolumn{2}{|c|}{0,9} & \multicolumn{2}{|c|}{$1,7^{(4)}$} \\
\hline
\end{tabular}


por: ácido glutâmico, ácido aspártico, arginina, serina, alanina, glicina, tirosina, prolina e cisteína (Tabela 2). Diferenças significativas pelo teste t, para locais, somente foram obtidas para glicina e alanina e verificaram-se os maiores teores em Santa Maria.

Quanto aos aminoácidos não-essenciais, foi possível identificar cultivares de feijão com melhor característica para cada local de cultivo. A cultivar Iapar 31 apresentou elevados teores de ácido aspártico, ácido glutâmico, serina, glicina e prolina, quando cultivada em Santa Maria (Tabela 2). Entretanto, em Pelotas, a cultivar Macotaço se destacou pelos elevados teores de ácido aspártico, ácido glutâmico, serina, glicina, alanina, prolina e arginina.

De acordo com a composição de aminoácidos, das proteínas das cultivares de feijão, foram identificados dois grupos de cultivares com $65 \%$ de dissimilaridade genética (Figura 1). O grupo 1 foi constituído pelas cultivares Diamante Negro, Guateian 6662, TPS Nobre,

Tabela 2. Composição de aminoácidos não essenciais (em gramas por $16 \mathrm{~g}$ de $\mathrm{N}$ da matéria seca) e de proteína bruta (em gramas por $100 \mathrm{~g}$ de matéria seca) dos grãos de cultivares de feijão cultivadas em Santa Maria (SM) e em Pelotas (Pel), RS.

\begin{tabular}{|c|c|c|c|c|c|c|c|c|c|c|c|c|c|c|c|c|c|c|c|}
\hline \multirow[t]{2}{*}{ Cultivar } & \multicolumn{2}{|c|}{$\begin{array}{c}\text { Ácido } \\
\text { aspártico }\end{array}$} & \multicolumn{2}{|c|}{$\begin{array}{l}\text { Ácido } \\
\text { glutâmico }\end{array}$} & \multicolumn{2}{|c|}{ Serina } & \multicolumn{2}{|c|}{ Glicina } & \multicolumn{2}{|c|}{ Alanina } & Prolina & \multicolumn{2}{|c|}{ Tirosina } & \multicolumn{2}{|c|}{ Arginina } & \multicolumn{2}{|c|}{ Cisteína } & \multicolumn{2}{|c|}{ Proteína bruta } \\
\hline & SM & Pel & SM & Pel & SM & $\overline{\mathrm{Pel}}$ & SM & $\overline{\mathrm{Pel}}$ & SM & $\overline{\mathrm{Pel}}$ & SM Pel & SM & $\overline{\mathrm{Pel}}$ & SM & $\overline{\mathrm{Pel}}$ & SM & $\overline{\mathrm{Pel}}$ & SM & Pel \\
\hline & \multicolumn{19}{|c|}{ Grupo preto } \\
\hline TPSBionobre & 16,29 & 13,22 & 19,00 & 15,73 & 5,89 & 5,09 & 3,40 & 2,84 & 3,67 & 3,46 & $2,641,73$ & 2,98 & 2,78 & 8,11 & 6,40 & 1,26 & 1,21 & 29,31 & 33,77 \\
\hline BRSValente & 16,04 & 13,29 & 18,25 & 15,11 & 6,07 & 5,10 & 2,70 & 2,82 & 3,52 & 3,44 & $1,801,91$ & 2,44 & 2,75 & 7,34 & 6,91 & 1,20 & 1,10 & 29,90 & 36,09 \\
\hline FTS Soberano & 14,69 & 16,04 & 15,46 & 19,42 & 5,06 & 6,08 & 2,78 & 3,51 & 3,55 & 3,48 & $1,791,95$ & 2,71 & 3,10 & 6,22 & 8,35 & 1,16 & 1,02 & 31,32 & 35,87 \\
\hline Guapo Brilhante & 14,37 & 14,61 & 17,36 & 18,04 & 6,34 & 5,69 & 3,69 & 3,23 & 3,73 & 3,47 & $2,392,32$ & 2,91 & 2,83 & 6,38 & 7,17 & 1,09 & 1,11 & 25,80 & 33,58 \\
\hline Diamante Negro & 13,92 & 13,55 & 15,93 & 16,09 & 6,11 & 5,28 & 3,40 & 2,90 & 3,79 & 3,32 & $2,17 \quad 2,57$ & 3,02 & 2,66 & 6,61 & 6,76 & 0,97 & 1,00 & 28,99 & 36,80 \\
\hline TPSN & 13,79 & 13,54 & 16,14 & 16,31 & 6,08 & 5,28 & 3,49 & 2,99 & 3,91 & 3,46 & $2,28 \quad 1,93$ & 3,04 & 3,20 & 6,61 & 6,52 & 0,95 & 1,27 & 29,69 & 31,35 \\
\hline & 13,54 & 17,70 & 15,48 & 21,35 & 6,01 & 6,81 & 3,32 & 3,69 & 3,73 & 3,76 & $2,13 \quad 3,02$ & 2,99 & 3,09 & 6,49 & 9,76 & 0,97 & 1,16 & 29,81 & 32,09 \\
\hline dito & & 13,1 & 6,36 & 16,1 & 5,97 & 5,06 & 3,34 & 2,96 & 3,62 & 3,26 & 42,10 & 95 & 2,80 & 6,74 & 6,58 & 1,12 & 1,04 & 76 & 37,06 \\
\hline & 38 & 13,76 & 29 & 16,29 & 5,92 & 5,32 & 3,38 & 3,15 & 85 & 3,51 & 312,20 & 91 & 2,96 & 86 & 6,37 & 84 & 1,15 & 16 & 4,33 \\
\hline & 24 & 12,98 & 10 & 15,65 & 5,84 & 5,06 & 3,21 & 2,80 & 3,66 & 3,23 & $2,142,52$ & 2,87 & 2,73 & 6,50 & 5,96 &, 28 & 1,06 & 80 & 5,96 \\
\hline & 67 & 13,62 &, 34 & 16,80 & 5,17 & 5,29 & 3,33 & 2,93 & 3,60 & 3,34 & $2,412,52$ & 3,02 & 2,77 & 6,20 & 6,45 & 38 & 1,04 & 9,08 &, 65 \\
\hline Macanudo & 42 & 14,24 & 4,32 & 16,30 & 5,13 & 5,43 & 3,28 & 2,99 & 3,55 & 3,50 & $2,322,60$ & 3,01 & 2,86 & 5,91 & 7,30 & 1,39 & 1,13 & 28,96 & 35,42 \\
\hline \multirow[t]{2}{*}{ Minuano } & & 14,07 & & & & 5,46 & 3,34 & 3,08 & 3,62 & 3,64 & $2,391,89$ & & 2,68 & 6,20 & 7,88 & 1,43 & 1,06 & 28,19 & 34,14 \\
\hline & \multicolumn{19}{|c|}{ Grupo cor ${ }^{(1)}$} \\
\hline & ,42 & 14,14 & 0,69 & 16,85 & 6,71 & 5,62 & 3,82 & 2,98 & 4,16 & 3,42 & $2,68 \quad 1,71$ & 3,27 & 2,67 & 7,82 & 6,44 & 1,40 & 1,13 & 26,75 & 32,41 \\
\hline Iraí & 7,28 & 13,89 & 20,12 & 16,03 & 6,60 & 5,37 & 3,71 & 2,88 & 4,54 & 3,47 & $2,25 \quad 1,82$ & 3,44 & 2,88 & 6,51 & 6,03 & 1,74 & 1,26 & 24,78 & 32,03 \\
\hline TPSBonito & 15,78 & 14,41 & 19,45 & 17,14 & 6,15 & 5,86 & 2,94 & 3,20 & 3,63 & 3,57 & $2,062,05$ & 2,71 & 2,86 & 6,80 & 6,80 & 1,19 & 1,18 & 29,13 & 33,57 \\
\hline FTSMagnífico & 14,23 & 14,27 & 17,32 & 17,57 & 5,42 & 5,61 & 3,13 & 3,05 & 3,74 & 3,40 & $2,06 \quad 1,93$ & 2,94 & 2,77 & 6,71 & 7,44 & 1,22 & 1,06 & 29,77 & 36,32 \\
\hline & 13 & 13,00 & & 15,24 & 5,02 & 5,08 & 3,00 & 2,80 & 3,65 & 3,36 & $2,28 \quad 1,78$ & 3,00 & 2,80 & 7,66 & 6,76 & 1,23 & 1,1 & 30,93 & 34,56 \\
\hline Carioca & 69 & 13,39 & 15,52 & 15,49 & 5,09 & 5,36 & 2,92 & 2,94 & 3,52 & 3,47 & $1,95 \quad 1,82$ & 2,69 & 2,80 & 7,89 & 6,77 & 1,23 & 1,30 & 29,42 & 31,94 \\
\hline Média & 18 & 14,05 & 16,73 & 16,74 & 5,75 & 5,47 & $3,27 *$ & $3,04^{*}$ & $3,74^{*}$ & $3,45^{*}$ & $2,22 \quad 2,13$ & 2,94 & 2,84 & 6,82 & 6,98 & 1,21 & 1,13 & $29,40^{*}$ & $34,36^{*}$ \\
\hline & 42 & 17,70 & 20,69 & 21,35 & 6,71 & 6,81 & 3,82 & 3,69 & 4,54 & 3,76 & $2,68 \quad 3,02$ & 3,44 & 3,20 & 8,11 & 9,76 & 1,74 & 1,30 & 33,16 & 37,06 \\
\hline & 11,02 & 12,98 & 14,32 & 15,11 & 4,65 & 5,06 & 2,70 & 2,80 & 3,52 & 3,23 & $1,79 \quad 1,71$ & 2,44 & 2,66 & 5,91 & 5,96 & 0,84 & 1,00 & 24,78 & 31,35 \\
\hline Desvio-padrão & 1,79 & 1,14 & 1,91 & 1,52 & 0,58 & 0,43 & 0,31 & 0,24 & 0,25 & 0,12 & $0,24 \quad 0,37$ & 0,21 & 0,15 & 0,64 & 0,90 & 0,21 & 0,09 & 2,05 & 1,81 \\
\hline
\end{tabular}

${ }^{(1)}$ Cultivares de grãos carioca, exceto a Iraí que apresenta grãos beje, com estrias vermelhas. *Significativo pelo teste t, a $5 \%$ de probabilidade.

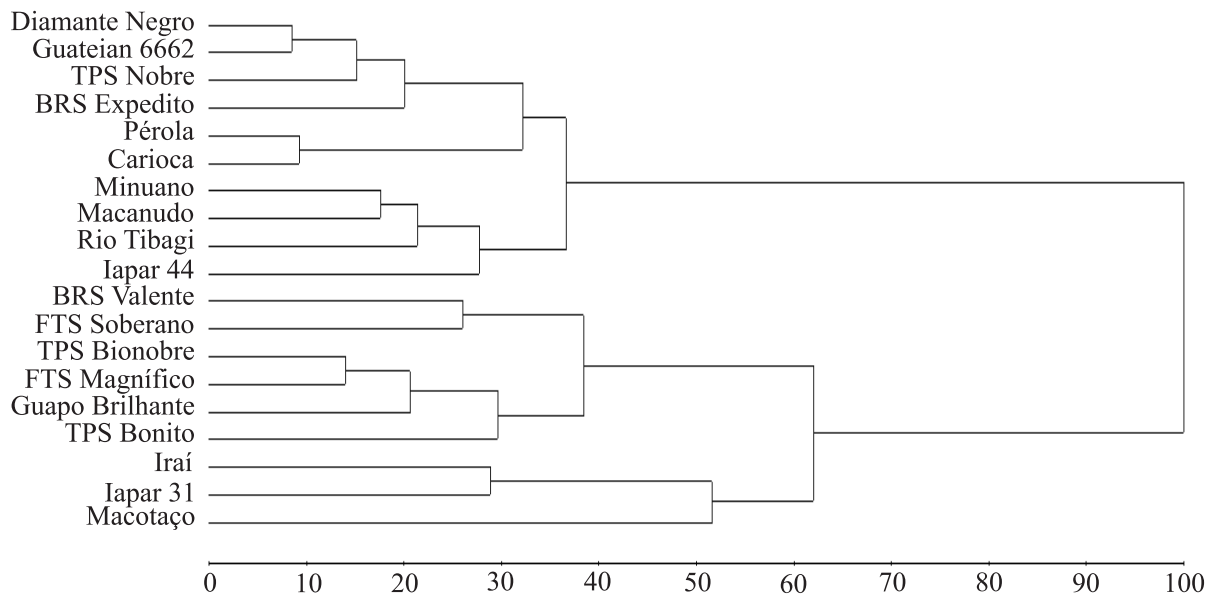

Figura 1. Dendrograma de dissimilaridade genética entre 19 cultivares de feijão, obtido pelo método de agrupamento vizinho mais distante, baseado na distância euclidiana média. 
BRS Expedito, Pérola, Carioca, Minuano, Macanudo, Rio Tibagi e Iapar 44. O grupo 2 foi formado pelas demais cultivares (BRS Valente, FTS Soberano, TPS Bionobre, FTS Magnífico, Guapo Brilhante, TPS Bonito, Iraí, Iapar 31 e Macotaço).

Com base na matriz da distância euclidiana média, as cultivares Diamante Negro e Guateian 6662 foram as mais similares $(0,1005)$, enquanto Minuano e Iapar 31 foram as mais dissimilares $(1,1805)$. A identificação de similaridade genética possibilita a melhor sistematização na conservação de germoplasma, evitando-se que amostras muito similares sejam preservadas como acessos diferenciados. Além disso, a realização de cruzamentos entre germoplasma não aparentado (dissimilar), pode aumentar as chances de obtenção de populações segregantes, com variabilidade genética superior em plantas autógamas.

$\mathrm{O}$ teor de metionina apresentou correlação positiva com os teores de lisina $(r=0,60)$, serina $(r=0,54)$, glicina $(\mathrm{r}=0,55)$, alanina $(\mathrm{r}=0,47)$ e tirosina $(\mathrm{r}=0,55)$ (Tabela 3). Dessa maneira, a seleção para aumento do teor de metionina será eficiente também para o incremento de lisina, serina, glicina, alanina e tirosina, e uma cultivar com maior valor protéico agregado poderá ser obtida pelo melhoramento genético. Kelly \& Bliss (1975a) obtiveram moderada herdabilidade quanto à metionina, no sentido restrito, em diferentes populações de feijão, portanto a seleção de linhagens com teores elevados desse aminoácido poderá ser efetiva em populações com variabilidade genética.

Com relação à cisteína, obteve-se coeficiente de correlação linear positivo com a lisina $(r=0,48)$, isoleucina $(r=0,57)$ e valina $(r=0,75)$, e para os demais aminoácidos não se verificou correlação. Nenhuma correlação negativa foi obtida entre pares de aminoácidos (Tabela 3), o que indica que a seleção para maior teor de determinado aminoácido não comprometerá o teor de outro, e que será possível desenvolver germoplasma com teores de aminoácidos adequados, para satisfazer as necessidades nutricionais diárias de crianças e de adultos.

Considerando-se que grande parte da população brasileira tem acesso limitado às proteínas de origem animal, a identificação de plantas com melhor qualidade de proteína é extremamente oportuna, para a manutenção do estado de saúde e para a prevenção de várias doenças. Por isso, a utilização de grãos de feijão da cultivar Iraí na alimentação deverá ser melhor investigada, pois, pelas características apresentadas, seu consumo é benéfico. Essa cultivar pode ser usada como genitora, em programas de hibridação controlada, para o desenvolvimento de germoplasma de melhor qualidade protéica.

Tabela 3. Matriz de coeficientes de correlação fenotípica entre os aminoácidos (em gramas por $16 \mathrm{~g}$ de $\mathrm{N}$ da matéria seca) de grãos de cultivares de feijão cultivadas em Santa Maria e em Pelotas, $\operatorname{RS}^{(1)}$.

\begin{tabular}{|c|c|c|c|c|c|c|c|c|c|c|c|c|c|c|c|c|}
\hline Aminoácido & Lys & Phe & Leu & Ile & His & Val & Thr & Met & Asp & Glu & Ser & Gly & Ala & Pro & Tyr & Cys \\
\hline Phe & $0,86^{*}$ & & & & & & & & & & & & & & & \\
\hline Leu & $0,69 *$ & $0,68 *$ & & & & & & & & & & & & & & \\
\hline Ile & $0,82 *$ & $0,77 *$ & $0,77^{*}$ & & & & & & & & & & & & & \\
\hline His & $0,51 *$ & $0,56^{*}$ & 0,43 & 0,42 & & & & & & & & & & & & \\
\hline Val & $0,71 *$ & $0,72 *$ & $0,49^{*}$ & $0,86^{*}$ & 0,34 & & & & & & & & & & & \\
\hline Thr & $0,54 *$ & $0,67 *$ & 0,27 & 0,45 & $0,78 *$ & $0,52 *$ & & & & & & & & & & \\
\hline Met & $0,60^{*}$ & 0,41 & 0,43 & 0,21 & 0,36 & $-0,03$ & 0,25 & & & & & & & & & \\
\hline Asp & 0,44 & $0,64 *$ & 0,30 & 0,33 & $0,52 *$ & 0,23 & $0,75^{*}$ & 0,44 & & & & & & & & \\
\hline Glu & 0,42 & $0,61 *$ & 0,30 & 0,37 & $0,70^{*}$ & 0,23 & $0,78^{*}$ & 0,34 & $0,91^{*}$ & & & & & & & \\
\hline Ser & 0,40 & $0,52 *$ & $0,52 *$ & 0,26 & $0,68^{*}$ & 0,03 & $0,68 *$ & $0,54^{*}$ & $0,80^{*}$ & $0,83 *$ & & & & & & \\
\hline Gly & $0,57 *$ & $0,52 *$ & $0,55^{*}$ & 0,40 & $0,78^{*}$ & 0,25 & $0,54^{*}$ & $0,55^{*}$ & 0,34 & $0,52 *$ & $0,66^{*}$ & & & & & \\
\hline Ala & $0,81^{*}$ & $0,72 *$ & $0,70^{*}$ & $0,79^{*}$ & $0,56^{*}$ & $0,67 *$ & $0,68^{*}$ & $0,47^{*}$ & $0,57^{*}$ & $0,57^{*}$ & $0,62 *$ & $0,64^{*}$ & & & & \\
\hline Pro & 0,08 & $-0,02$ & 0,22 & $-0,08$ & $0,46^{*}$ & $-0,07$ & 0,12 & 0,17 & $-0,22$ & $-0,05$ & 0,24 & $0,56^{*}$ & 0,07 & & & \\
\hline Tyr & $0,77^{*}$ & $0,59^{*}$ & $0,78^{*}$ & $0,70 *$ & $0,55^{*}$ & $0,53^{*}$ & 0,31 & $0,55^{*}$ & 0,24 & 0,28 & 0,37 & $0,69^{*}$ & $0,72 *$ & 0,31 & & \\
\hline Cys & $0,48^{*}$ & 0,42 & 0,14 & $0,57 *$ & 0,11 & $0,75^{*}$ & 0,39 & $-0,11$ & 0,14 & 0,15 & $-0,11$ & $-0,08$ & 0,43 & $-0,24$ & 0,24 & \\
\hline Arg & $-0,06$ & 0,04 & $-0,30$ & $-0,25$ & 0,30 & $-0,06$ & 0,43 & 0,16 & 0,44 & 0,36 & 0,22 & 0,09 & 0,01 & $-0,12$ & $-0,12$ & $-0,18$ \\
\hline
\end{tabular}

${ }^{(1)}$ Lys, lisina; Phe, fenilalanina; Leu, leucina; Ile, isoleucina; His, histidina; Val, valina; Thr, treonina; Met, metionina; Asp, ácido aspártico; Glu, ácido glutâmico; Ser, serina; Gly, glicina; Ala, alanina; Pro, prolina; Tyr, tirosina; Cys, cisteína; Arg, arginina. *Significativo pelo teste t, a $5 \%$ de probabilidade, com 17 graus de liberdade. 


\section{Conclusões}

1. Os grãos das cultivares de feijão são constituídos, em ordem decrescente, pelos aminoácidos essenciais: leucina, lisina, fenilalanina, valina, isoleucina, treonina, histidina e metionina; e pelos aminoácidos não-essenciais: ácido glutâmico, ácido aspártico, arginina, serina, alanina, glicina, tirosina, prolina e cisteína.

2. Os teores de leucina, isoleucina, histidina, valina, treonina, glicina e alanina são afetados pela interação cultivares x locais.

3. A cultivar Iraí apresenta composição de aminoácidos adequada e é indicada para a composição de dietas e para derivações em programas de melhoramento.

\section{Agradecimentos}

Ao CNPq, à Capes e à Fapergs; ao pesquisador Irajá Ferreira Antunes, pelo envio de amostras de sementes de feijão.

\section{Referências}

ABD-EL-SAMEI, M.H.; LÁSZTITY, R. Comparative study on the amino acids composition in three local Phaseolus vulgaris seeds varieties. Zeitschrift für Lebensmitteluntersuchung und Forschung A, v.178, p.24-26, 1984.

ANTUNES, P.L.; BILHALVA, A.B.; ELIAS, M.C.; SOARES, G.J.D. Valor nutricional de feijão (Phaseolus vulgaris L.), cultivares Rico 23, Carioca, Piratã-1 e Rosinha-G2. Revista Brasileira de Agrociência, v.1, p.12-18, 1995.

ASSOCIATION OF OFFICIAL AGRICULTURAL CHEMISTS. Official methods of analysis. $16^{\text {th }}$ ed. Washington: AOAC, 1995. 200p.

COMISSÃO ESTADUAL DE PESQUISA DE FEIJÃO. Indicações técnicas para a cultura do feijão no Rio Grande do Sul 2003/04. Passo Fundo: UPF, 2003. 149p.

COSTA, N.M.B. Alimentos: componentes nutricionais e funcionais. In: COSTA, N.M.B.; BORÉM, A. (Ed.). Biotecnologia e nutrição: saiba como o DNA pode enriquecer os alimentos. São Paulo: Nobel, 2003. p.31-69.

CRUZ, C.D. Programa GENES: aplicativo computacional em genética e melhoramento. Viçosa: UFV, 2001. 648p.

CRUZ, C.D.; REGAZZI, A.J. Modelos biométricos aplicados ao melhoramento genético. 2.ed. Viçosa: UFV, 2001. 390p.

EVANS, R.J.; BANDEMER, S.L. Nutritive value of legume seed proteins. Journal of Agricultural and Food Chemistry, v.15, p.439-443, 1967.

FAO. Junta de Conselho de Especialistas FAO/WHO/ONU. Necessidades de energia e proteína. São Paulo: Roca, 1998. 225p.

FONSECA MARQUES, M.F.; BORA, P.S. Composición química y análisis de aminoácidos de alubias. Ciencia y Tecnología Alimentaria, v.2, p.248-252, 2000.

FRANCO, G. Tabela de composição química dos alimentos. 9.ed. Rio de Janeiro: Atheneu, 2005. 307p.

GUZMÁN-MALDONADO, S.H.; ACOSTA-GALLEGOS, J.; PAREDES-LÓPEZ, O. Protein and mineral content of a novel collection of wild and weedy common bean (Phaseolus vulgaris L). Journal of the Science of Food and Agriculture, v.80, p.1874$1881,2000$.

KELLY, J.D.; BLISS, F.A. Heritability estimates of percentage seed protein and available methionine and correlations with yield in dry beans. Crop Science, v.15, p.753-757, 1975a.

KELLY, J.D.; BLISS, F.A. Quality factors affecting the nutritive value of bean seed protein. Crop Science, v.15, p.757-760, 1975 b.

MORALES DE LEON, J.; BOURGES, H.; CAMACHO, M.E. Amino acid composition of some Mexican foods. Archivos Latinoamericanos de Nutrición, v.55, p.172-186, 2005.

PIRES, C.V.; OLIVEIRA M.G.A.; ROSA, J.C.; COSTA, N.M.B. Qualidade nutricional e escore químico de aminoácidos de diferentes fontes protéicas. Ciência e Tecnologia dos Alimentos, v.26, p.179187, 2006.

ROLAS. Recomendações de adubação e calagem para os estados do Rio Grande do Sul e Santa Catarina. 3ed. Passo Fundo: SBCS, 1995. 223p.

SZARFARC, S.C.; MARTINS, I.S.; MAZZILLI, R.N.; CAVALCANTI, M.L.F.; GANDRA, Y.R. Qualidade protéica de dietas avaliadas segundo os padrões FAO, 1968 e FAO, 1973. Revista de Saúde Pública, v.14, p.151-160, 1980.

Recebido em 4 de julho de 2007 e aprovado em 20 de setembro de 2007 